\title{
Medication use by adults in greater Manaus: a population-based cross-sectional study, 2015
}

\author{
Vanessa Gomes Lima ${ }^{\circledR 1,2^{*}}$, Marcus Tolentino Silva ${ }^{1,3}$, Taís Freire Galvão ${ }^{1,4}$ \\ 'Programa de Pós-graduação em Ciências Farmacêuticas, Universidade Federal do Amazonas, \\ Manaus, Amazonas, Brazil, ${ }^{2}$ Maternidade Azilda da Silva Marreiro, Secretaria Estadual de \\ Saúde do Amazonas, Manaus, Amazonas, Brazil, ${ }^{3}$ Programa de Pós-graduação em Ciências \\ Farmacêuticas, Universidade de Sorocaba, Sorocaba, São Paulo, Brazil, ${ }^{4}$ Faculdade de \\ Ciências Farmacêuticas, Universidade Estadual de Campinas, Campinas, São Paulo, Brazil
}

\begin{abstract}
The use of medicines can be an indicator of healthcare access. Our aim was to evaluate the consumption of medicine and associated factors among adults in Manaus Metropolitan Region, located in the north of Brazil. A cross-sectional population-based study was conducted with adults, $\geq 18$ years old, selected by probabilistic sampling. The outcome was the use of medicine in the previous 15 days. Poisson regression with robust variance was used to calculate the prevalence ratio (PR) of medicine consumption, with $95 \%$ confidence interval (CI). Use of medicines was reported by $29 \%$ (95\% CI: 28 $31 \%$ ) of the participants. People with good (PR: 0.82, 95\% CI: 0.72-0.94) and fair (PR: 0.77, 95\% CI: 0.65-0.90) health status were shown to use less medication than those with very good health. People with partners (PR: 1.19, 95\% CI: 1.08-1.31), and people who had sought healthcare service in the fortnight (PR: 2.16, 95\% CI: 1.97-2.37) showed higher medicine consumption. Medical prescription (80.1\%) was the main inductor of consumption; purchasing at a drug store (46.4\%), and acquiring through the Brazilian Unified Health System (39.6\%) were the main ways to obtain medicines. About one-third of adults in the Metropolitan Region of Manaus used medicines regularly, mainly people with very good health, living with partners, and with recent use of a health service.
\end{abstract}

Keywords: Medication use. Cross-Sectional Studies. Adult. Manaus.

\section{INTRODUCTION}

The use and access to prescription drugs is influenced by several factors that may differ depending on the region in Brazil (Haque, 2017). Socioeconomic inequality is often identified as one of these factors, affecting the rate of medication use nationwide (Hoebert, Laing, Stephens, 2011). In order to cover health expenses, Brazilian citizens have to compromise the family budget; associated with other difficulties to obtain medicines, this constitutes an important barrier

*Correspondence: T. F. Galvao. Universidade Estadual de Campinas, Faculdade de Ciências Farmacêuticas. R. Cândido Portinari, 200 - Cidade Universitária Zeferino Vaz. Campinas/SP CEP: 13083-871. E-mail: taisgalvao@gmail.com to general access (Garcia, Sant'Anna, Magalhães et. al, 2013).

Research on the use of prescription drugs includes examining the practices of prescription, distribution, and consumption of medicine. Additionally, the research area offers interventions that may improve the quality of these practices, incorporating the results into the Brazilian public health context by strengthening health systems and scaling access (Wettermark, Martino, Elseviers, 2016).

The Metropolitan Region of Manaus is characterized by an unequal distribution of wealth, with buying power limited to a small portion of the population. The human development index of the state of Amazonas is medium but some municipalities have poor access to basic sanitation (PNUD 2013; Andrade, Gouveia, D’Ávila et. al, 2012). 
In this context, studies that evaluate the consumption of medicine in this region may reveal crucial information to help guide future actions in the area.

With the aim of assessing the use of medications and associated factors among adults in the Metropolitan Region of Manaus, we conducted a cross-sectional population-based study.

\section{MATERIAL AND METHODS}

\section{Design and participants}

A cross-sectional population-based study was conducted from May to August, 2015. This analysis, with the primary focus on the use of medicine, integrates a larger epidemiological study that evaluates the associated factors to access and use of health supplies and services in Manaus Metropolitan Region (Silva, Galvao, 2017).

Sample composition, sampling procedures and other methodological details of the research are available in an earlier paper (Silva, Galvao, 2017). In brief, the sample was comprised of 4,000 adults ( $\geq 18$ years old), selected by probabilistic sampling in three stages, by clusters, and stratified by sex and age.

\section{Data sources and measurement}

The following question was used to assess the outcome of the study: "In the last 15 days (two weeks), have you taken any medicine?" (yes, no). If the answer was "yes", the following questions were asked: "What is the name of the medicine?" (free answer); "For which illness or health problem are you using this medicine?" (free answer); "How long have you been taking this medicine?" (free answer); "Who recommended it?" (Doctor, pharmacist, own account, relatives or neighbors, drug store clerk, other); and "What was the mean of acquisition of the medicine?" (drug store, Brazil's Unified Health System, Brazil's Popular Pharmacy Program, health insurance, other). The name of the medicine was registered as informed by the interviewee, without confirmation by the package leaflet, packaging, or medical prescription.

After data collection, the products informed by the participants were identified according to the Brazilian Common Denomination, and then classified using the World Health Organization's Anatomical Therapeutic Chemical System (ATC), which consists of five ranking levels (WHO, 2019). Tabulated drugs that were impossible to categorize, due to the name being indecipherable or unlisted in the anatomicaltherapeutic classification system, were labeled as non-codifiable.

Independent variables were sex (male, female), age (in years), marital status (single or married/stable union), number of people living at the participant's residence (two, three to five, six or more), education level (higher education, complete high school, complete basic education, incomplete basic education, or illiterate), work status (unemployed or employed), economic classification (A/B [wealthiest], C [middle], $\mathrm{D} / \mathrm{E}$ [poorest]), self-reported health status (very good, good, fair, poor, very poor), presence of chronic diseases (none, one, two or more), use of health services in the last 15 days (yes, no), need for hospitalization in the last 12 months (yes, no), and health insurance coverage (yes, no).

\section{Statistical methods}

In the descriptive analysis, all the variables that characterized the sample and the use of medicines were evaluated. Prevalence ratio (PR) of medicine consumption and 95\% confidence interval (CI) were calculated in bivariate analysis to identify the associated factors of medicine consumption. Variables significant at $\mathrm{p}<0.10$ level were included in the adjusted Poisson regression analysis with robust variance, and association with drug consumption was positively determined when $p<0.05$. Significance of variables was calculated by Wald test. The probability of the results with $95 \%$ CI by two significant variables in the adjusted analysis was calculated. This predictive model was calculated by linearized estimate of standard errors. All statistical analyses were performed in Stata software (version 14.2) and took into account the complex sampling of the research (svy command). No data was inputted whenever information was missing.

\section{Ethics}

The project was submitted and approved by the Research Ethics Committee of the Federal University of Amazonas, through the Opinion 974,428/2015, with the Certificate of Presentation for Ethical Assessment 42203615.4.0000.5020. The participants consented to engage in the research by signing a consent form. 


\section{RESULTS}

From a total of 4,001 participants, $52.8 \%$ were women, and $71 \%$ aged between 18 and 45 years old. The majority of the participants (47.6\%) had completed high school, reported living with a partner $(52.5 \%)$, belonged to economic classification $\mathrm{C}(57.1 \%)$, were employed (78.2\%), and lived in a house with three to five residents (57\%); 86.9\% lacked health insurance, $54.4 \%$ considered their health to be good, $59.6 \%$ had a diagnosis of at least one chronic illness, and $20.9 \%$ had resorted to healthcare services in the 15 days prior to the interview (Table I).

TABLE I - Characteristics of the population and frequency of use of medicines in the 15 days prior to data collection, Manaus Metropolitan Region, 2015 ( $n=4,001)$

\begin{tabular}{|c|c|c|c|}
\hline Variables & $\mathbf{N}$ & $\%$ & $\begin{array}{c}\% \\
\text { consumption }\end{array}$ \\
\hline
\end{tabular}

Sex

Female

$$
2,113
$$

52.8

28.0

Male

$$
1,888
$$

47.2

30.9

Age group (years)

$18-25$

26-35

$36-45$

46-59

60 or more

Marital status

Single

1,899

47.5

25.8

Married/stable union

2,102

52.5

32.7

Number of residents

in household

$$
\text { Two }
$$

25.5
TABLE I - Characteristics of the population and frequency of use of medicines in the 15 days prior to data collection, Manaus Metropolitan Region, 2015 ( $n=4,001)$

\begin{tabular}{lccc}
\hline Variables & $\mathbf{N}$ & $\mathbf{\%}$ & $\begin{array}{c}\% \\
\text { consumption }\end{array}$ \\
\hline Three to five & 2,274 & 56.8 & 29.7 \\
Six or more & 873 & 21.8 & 32.3
\end{tabular}

Economic classification

$\begin{array}{lccc}\mathrm{A} / \mathrm{B} & 629 & 15.7 & 28.5 \\ \mathrm{C} & 2,285 & 57.1 & 29.5 \\ \mathrm{D} / \mathrm{E} & 1,087 & 27.2 & 29.8\end{array}$

Work status

Unemployed

Employed

$871-21.8$

28.8

Education

Higher education

$158 \quad 4.0$

32.3

High school

$1,903 \quad 47.6$

29.3

Middle school

$649 \quad 16.2$

31.1

Elementary school

$536 \quad 13.4$

29.3

Less than elementary

755

18.9

27.7

Health insurance

No

3,478

86.9

29.4

Yes

523

13.1

29.6

Health status

Very good

471

11.8

37.6

Good

$2,175 \quad 54.4$

29.0

Fair

$1,108 \quad 27.7$

26.9 
TABLE I - Characteristics of the population and frequency of use of medicines in the 15 days prior to data collection, Manaus Metropolitan Region, 2015 ( $n=4,001)$

\begin{tabular}{lccc}
\hline Variables & $\mathbf{N}$ & $\mathbf{\%}$ & $\begin{array}{c}\% \\
\text { consumption }\end{array}$ \\
\hline Poor & 193 & 4.8 & 29.0 \\
Very poor & 54 & 1.4 & 27.8 \\
Chronic diseases & 1,617 & 40.4 & 31.3 \\
None & 1,147 & 28.7 & 28.0 \\
One & 1,237 & 30.9 & 28.2 \\
Two or more & & & \\
$\begin{array}{l}\text { Use of health services } \\
\text { (previous 15 days) }\end{array}$ & & & \\
No & 3,163 & 79.1 & 23.4 \\
Yes & 838 & 20.9 & 51.9 \\
\hline
\end{tabular}

Twenty-nine percent (95\% CI: 28-31\%) had consumed medication 15 days prior to the interview. The average number of medicines consumed per person was $1.50 \pm 2.74$, totaling 1,760 drugs. The prevalence of consumption on the day of the interview was $15 \%(95 \%$ CI: $14-17 \%$; data not shown in tables).

Using the ATC system, 1,703 drugs (97\%) were classified, while 57 drugs were non-codifiable. The most commonly used pharmacological groups were analgesics (18.2\%), renin-angiotensin system agents $(12.5 \%)$, antiinflammatory and antirheumatic drugs (11.6\%; Table II). The most consumed drugs were dipyrone (13.3\%), losartan (6.7\%) and diclofenac (4.8\%; data not shown in tables).
TABLE II - Medicines used in the 15 days prior to data collection according to pharmacological classes (third level of the anatomical-therapeutic classification system [ATC], N = 1,760 medicines), Manaus Metropolitan Region, 2015

\begin{tabular}{lccc}
\hline Categorical variables & ATC & n & \% \\
\hline Analgesics & N02 & 320 & 18.2 \\
$\begin{array}{l}\text { Agents acting on the renin- } \\
\begin{array}{l}\text { angiotensin system } \\
\text { No9 }\end{array}\end{array}$ & 220 & 12.5 \\
\hline
\end{tabular}

Anti-inflammatory and

antirheumatic products

M01 $204 \quad 11.6$

Antibacterial for systemic use

$\begin{array}{lll}\mathrm{J} 01 & 144 & 8.2\end{array}$

Drugs used in diabetes

A10 $\quad 106 \quad 6.0$

Drugs for acid related disorders

A02 $75 \quad 4.3$

Beta blocking agents

$\begin{array}{lll}\mathrm{C} 07 & 62 & 3.5\end{array}$

Vitamins

A11 $54 \quad 3.1$

Antithrombotic agents

$\begin{array}{lll}\text { B01 } & 49 & 2.8\end{array}$

Lipid modifying agents

$\begin{array}{lll}\mathrm{C} 10 & 49 & 2.8\end{array}$

Psycholeptics

N05 $\quad 43 \quad 2.4$

Diuretics

$\begin{array}{lll}\mathrm{C} 03 & 40 & 2.3\end{array}$

Sex hormones and modulators

of the genital system

$\begin{array}{lll}\mathrm{G} 03 & 30 & 1.7\end{array}$

Calcium channel blockers

$\begin{array}{lll}\mathrm{C} 08 & 30 & 1.7\end{array}$

Others categories $277 \quad 15.7$

ATC not codified $57 \quad 3.2$

Total $1,760100.0$

Note: ATC not codified, classification was not possible

Physicians were the main responsible for recommending medicines, having prescribed $80.1 \%$ of the drugs consumed by the participants in the two weeks prior to the interview ( $n=1,409$ medicines), followed by 
participant's own account (13.3\%; n=234 medicines), and indication of relatives and neighbors $(3.7 \% ; n=65$ medicines). Recommendation by the pharmacist was reported in 40 cases $(2.3 \%)$, and 4 by the drug store clerk $(0.2 \%$; Table III).

TABLE III - Responsible for recommendation and form of acquisition of the medicines used in the 15 days prior to data collection, Metropolitan Region of Manaus, 2015 ( $\mathrm{n}=1,760$ medicines)

\begin{tabular}{lcc}
\hline Responsible for recommendation of the medicines & $\mathbf{n}$ & $\mathbf{\%}$ \\
\hline Physicians & 1,409 & 80.0 \\
Own account & 234 & 13.3 \\
Relatives and neighbors & 65 & 3.7 \\
Pharmacist & 40 & 2.3 \\
Other indication & 9 & 0.5 \\
Drug store clerk & 3 & 0.2 \\
\hline Total & 1,760 & 100.0 \\
\hline Form of acquisition & $\mathrm{n}$ & $\%$ \\
Drug stores & 817 & 46.4 \\
Brazilian Unified Health System & 697 & 39.6 \\
Brazilian Popular Pharmacy Program & 169 & 9.6 \\
Other & 39 & 2.7 \\
Health insurance & 38 & 2.2 \\
\hline
\end{tabular}

About half of the medicines were purchased directly in drug stores (46.4\%), $40 \%$ of medicines were obtained from the Brazilian Unified Health System (SUS), and $10 \%$ through the Brazilian Popular Pharmacy Program (a program of co-payment or free provision by the government). Medicines obtained through health insurance were in the minority $(2.2 \%$; Table III).
In the bivariate analysis unadjusted, the consumption was positively associated with the following variables: males, households with more than three people, people who have a partner, and people who have sought healthcare services in the previous 15 days. Good and fair health status were negatively associated with the use of medicines when compared to the status of a very good health (Table IV). 
TABLE IV - Prevalence ratio (PR) of use of medicines in the 15 days prior to data collection ( $95 \% \mathrm{CI}$ ), Manaus Metropolitan Region, 2015

\begin{tabular}{|c|c|c|c|c|}
\hline \multirow{2}{*}{ Characteristics } & \multicolumn{2}{|c|}{ Unadjusted analysis } & \multicolumn{2}{|c|}{ Adjusted analysis } \\
\hline & PR (95\% CI) & p-value & PR $(95 \% C I)$ & p-value \\
\hline Sex & & 0.040 & & 0.106 \\
\hline Female & 1.00 & & 1.00 & \\
\hline Male & $1.11(1.00-1.22)$ & & $1.08(0.98-1.19)$ & \\
\hline Age group (years) & & 0.501 & & \\
\hline $18-25$ & 1.00 & & & \\
\hline $26-35$ & $1.02(0.89-1.16)$ & & & \\
\hline $36-45$ & $0.90(0.77-1.05)$ & & & \\
\hline $46-59$ & $0.96(0.82-1.12)$ & & & \\
\hline 60 or more & $0.97(0.81-1.17)$ & & & \\
\hline Marital status & & $<0.001$ & & \\
\hline Single & 1.00 & & 1.00 & \\
\hline Married/stable union & $1.27(1.15-1.40)$ & & $1.19(1.08-1.31)$ & $<0.001$ \\
\hline Number of residents in household & & 0.008 & & 0.209 \\
\hline Two & 1.00 & & 1.00 & \\
\hline Three to five & $1.16(1.02-1.33)$ & & $1.07(0.94-1.22)$ & \\
\hline Six or more & $1.27(1.09-1.47)$ & & $1.14(0.99-1.32)$ & \\
\hline Economic classification & & 0.834 & & \\
\hline $\mathrm{A} / \mathrm{B}$ & 1.00 & & & \\
\hline $\mathrm{C}$ & $1.04(0.90-1.19)$ & & & \\
\hline $\mathrm{D} / \mathrm{E}$ & $1.05(0.90-1.22)$ & & & \\
\hline Work status & & 0.656 & & \\
\hline Unemployed & 1.00 & & & \\
\hline Employed & $1.03(0.91-1.16)$ & & & \\
\hline
\end{tabular}


TABLE IV - Prevalence ratio (PR) of use of medicines in the 15 days prior to data collection ( $95 \% \mathrm{CI}$ ), Manaus Metropolitan Region, 2015

\begin{tabular}{|c|c|c|c|c|}
\hline \multirow{2}{*}{ Characteristics } & \multicolumn{2}{|c|}{ Unadjusted analysis } & \multicolumn{2}{|c|}{ Adjusted analysis } \\
\hline & PR (95\% CI) & p-value & PR (95\%CI) & p-value \\
\hline Education & & 0.681 & & \\
\hline Higher education & 1.00 & & & \\
\hline High school & $0.91(0.72-1.16)$ & & & \\
\hline Middle school & $0.97(0.75-1.25)$ & & & \\
\hline Elementary school & $0.92(0.71-1.19)$ & & & \\
\hline Less than elementary & $0.87(0.67-1.12)$ & & & \\
\hline Health insurance & & 0.944 & & \\
\hline No & 1.00 & & & \\
\hline Yes & $1.01(0.87-1.16)$ & & & \\
\hline Health status & & $<0.001$ & & 0.019 \\
\hline Very good & 1.00 & & 1.00 & \\
\hline Good & $0.77(0.67-0.88)$ & & $0.82(0.72-0.94)$ & \\
\hline Fair & $0.71(0.61-0.83)$ & & $0.77(0.65-0.90)$ & \\
\hline Poor & $0.77(0.60-0.98)$ & & $0.78(0.60-1.02)$ & \\
\hline Very poor & $0.74(0.47-1.15)$ & & $0.78(0.49-1.25)$ & \\
\hline Chronic diseases & & 0.097 & & 0.341 \\
\hline None & 1.00 & & 1.00 & \\
\hline One & $0.90(0.80-1.01)$ & & $0.92(0.82-1.03)$ & \\
\hline Two or more & $0.90(0.80-1.01)$ & & $0.99(0.87-1.12)$ & \\
\hline Use of health services (previous 15 days) & & $<0.001$ & & $<0.001$ \\
\hline No & 1.00 & & 1.00 & \\
\hline Yes & $2.2(2.02-2.42)$ & & $2.16(1.97-2.37)$ & \\
\hline
\end{tabular}


The use of medicines adjusted for the significant variables in the bivariate analysis was higher among people who had a partner (PR: $1.19 ; 95 \%$ CI: 1.08-1.31), and people who had sought healthcare services in the previous 15 days (PR: 2.16; 95\% CI: 1.97-2.37). People with good (PR: 0.82; 95\% CI: 0.72-0.94) and fair (PR: 0.77 ; $95 \%$ CI: $0.65-0.90)$ perception of health status used less medication than those reporting very good health. Male and number of residents per household lost significance in the adjusted analysis. The age, education level, income and health insurance variables were not associated with the use of medicines in this research.

The probability of medicine use was $64 \%(95 \%$ CI: $56-72 \%, p<0.001)$ in people with very good health status that had used health services in the previous 15 days, and 22\% (95\% CI: $12-32 \%, \mathrm{p}<0.001$; Figure I) in adults with very poor health that had not used health services in the same period.

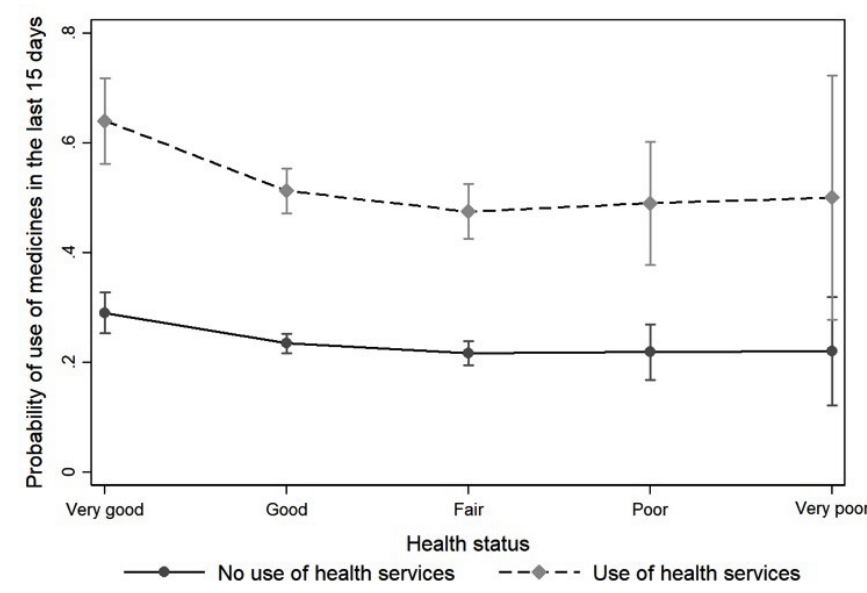

FIGURE 1 - Predictive probability of use of medicines according to the health status and use of health services in the 15 days prior to data collection.

\section{DISCUSSION}

About one third of the adults in the Metropolitan Region of Manaus had consumed medicines in the 15 days previous to the research. The consumption was significantly higher among people with very good health status, people who have a partner, and people who have used healthcare services in the period. Age, number of residents, economic class, occupation, education level, health insurance, and chronic disease showed no association with the use of medicines.
Cross-sectional studies based on self-reports have limitations, particularly on the reliability of the information. The affirmative responses to the use of medication were not confronted with package leaflet inserts, prescriptions, packages or any other evidence of consumption, in order to avoid underreporting (Wettermark, Martino, Elseviers, 2016). Although this decision may represent a risk of measurement bias, it is often adopted in these situations.

The present research was based on previous drug utilization population-based studies held in Brazil, which employ more frequent variables and recall periods (Gomes, Silva, Galvão, 2017). Previous analyses of this outcome in this region were absent. The representative sampling adopted allows the generalization of the results for the population of this region.

The prevalence of medication use in the 15 days period was lower than the Brazilian prevalence calculated in the meta-analysis of studies with population representativeness (Gomes, Silva, Galvão, 2017), and in the National Survey on Access, Use and Promotion of Rational Use of Medicines (PNAUM) (Bermudez, Barros, 2016), which observed use of medication by about half of adults in a month prior. This difference may be due to the methodological and regional differences, as well as to the pharmaceutical policies of the period.

The use of medication in the previous 15 days was not associated with sex in this research. Previous population studies found higher consumption among women when compared to men (Gomes, Silva, Galvão, 2017; Pons, Knauth, Vigo et. al, 2017). However, although inferior when compared to women, drug consumption by men is also influenced by age, so much so that from the age of 40, their consumption can be compared to that of the elderly (Prado, Francisco, Bastos et. al, 2016).

Physicians were the main inducers of use of medication in the Metropolitan Region of Manaus, which is the same conclusion found in a population study conducted in Brasilia, where $90 \%$ of the use of medicines in the seven days prior to the interview was prescribed by a physician (Galvao, Silva, Gross et. al, 2014). Educational and prescriptive actions aimed at prescribers seem to be strategic to promote rational use of medication in that region. Physicians are often persuaded by the pharmaceutical industry, which results in higher rate of prescription of pharmaceutical products (DeJong, Aguilar, Tseng et. al, 2016; Fadare, Oshikoya, Ogunleye et. al, 2018). 
Two in ten medicines used in the fortnight period were self-prescribed (i.e. self-medication). A systematic review of representative surveys conducted in Brazil revealed that self-medication is frequent in one-third of the adult population (Domingues, Galvão, de Andrade et. al, 2015), appearing as an alternative to difficulties in access to healthcare services (Naves, Castro, Carvalho et. al, 2010). These results corroborate the national rate found in PNAUM, which showed that $16 \%$ of the population had used at least one medication without medical prescription in the fortnight (Arrais, Fernandes, Pizzol et. al, 2016).

Approximately half of the medicines consumed in the fortnight were obtained through public programs (Brazilian Unified Health System - SUS - and Brazilian Popular Pharmacy Program). Similarly, the 2008 National Sample Household Survey found that $45 \%$ of the population regularly access to medicines prescribed in SUS, and that the main reason for not obtaining the medicines was lack of money (52\%) (Boing, Bertoldi, Boing et. al, 2013).

The reduction in the list of medicines provided by the Brazilian Popular Pharmacy Program will likely impact access to medication by the Brazilian population (BRASIL, 2017). This and other austerity policies directed to SUS will potentially deteriorate the access and use of healthcare services and supplies, including medicines. A systematic review by Parmar, Stavropoulou, Ioannidis, 2016, assessed health outcomes of the economic crisis in Europe between 2008 and 2015, indicating an increase in the number of people who did not have access to medical services after the implementation of austerity measures.

Situations such as lack of diligence in the use of public funds, expenditures that do not meet the community's demand, investments limited to the Basic Component of Pharmaceutical Assistance, and exhaustion of the financing model weakened the basic healthcare system, corroborating the deficit generated by the cuts in SUS funding (Faleiros, Acurcio, Álvares et. al, 2017).

A higher rate of medicine use had a consistent positive association with the presence of a partner. This factor appears as an affective influence when seeking treatment and care (Duarte, Gianini, Ferreira et. al, 2012). People who reported very good health used more medicines, similar to the results of PNAUM, from 12,725 surveyed people in 2014: the ones with greater access to medicines evaluated their health status as good or very good (Oliveira, Luiza, Tavares et. al, 2016). Another survey conducted in 2017 in Rio Grande do Sul, Brazil, also presented a similar pattern (Cavalcanti, Doring, Portella et. al, 2017). People that consume medicines may present higher demand for healthcare services, as to prevent and treat diseases, which reflects in better health status.

In conclusion, we found that the use of medicines is associated with better health status, living with a partner, and usage of healthcare services. Medical prescription was the main indicator of the medicines consumed, thus, actions focused at prescribers may be effectively guide pharmaceutical assistance in the region. Half of the medicines were purchased directly by the user, reflecting economic constraints that may impact on the pharmacological treatment of this population. Moreover, future research should prioritize issues of inequity in access to medicines, as well as the impact of austerity measures on the population of the region.

\section{ACKNOWLEDGMENTS}

This research was funded by the National Council for scientific and Technology Development (CNPq, Grants 404990/2013-4 and 448093/2014-6). Vanessa Gomes Lima received a masters' scholarship from Amazonas Research Foundation (FAPEAM Grant 018/2015-POSGRAD 2015-UFAM).

\section{REFERENCES}

Andrade EdO, Gouveia VV, D’Ávila RL, Carneiro MB, Massud M, Gallo JH. Index of health development: conceptualization and reflections on its need. Rev Assoc Med Bras. 2012;58(4):413-21.

Arrais PSD, Fernandes MEP, Pizzol TdSD, Ramos LR, Mengue SS, Luiza VL, et al. Prevalence of self-medication in Brazil and associated factors. Revista de Saúde Pública. 2016;50(suppl 2):13s.

Bermudez JAZ, Barros MBdA. Profile of access and use of medicines in the Brazilian population contributions and challenges of PNAUM Household Survey. Rev Saude Publica. 2016;50(suppl 2):2s.

Boing AC, Bertoldi AD, Boing AF, Bastos JL, Peres KG. [Access to medicines in the public sector: analysis of users of the Brazilian Unified National Health System]. Cad Saude Publica. 2013;29(4):691-701. 
BRASIL. Conselho Nacional de Secretarias Municipais de Saúde (CONASEMS). Encerramento da rede própria do Farmácia Popular - Nota Informativa. 2017.

Cavalcanti G, Doring M, Portella MR, Bortoluzzi EC, Mascarelo A, Delani MP. Multimorbidity associated with polypharmacy and negative self-perception of health. Revista Brasileira de Geriatria e Gerontologia. 2017;20(5):634-42.

DeJong C, Aguilar T, Tseng CW, Lin GA, Boscardin WJ, Dudley RA. Pharmaceutical Industry-Sponsored Meals and Physician Prescribing Patterns for Medicare Beneficiaries. JAMA internal medicine. 2016;176(8):1114-22.

Domingues PHF, Galvão TF, de Andrade KRC, de Sá PTT, Silva MT, Pereira MG. Prevalence of self-medication in the adult population of Brazil: a systematic review. Rev Saude Publica. 2015;49:36.

Duarte LR, Gianini RJ, Ferreira LR, Camargo MAdS, Galhardo SD. Hábitos de consumo de medicamentos entre idosos usuários do SUS e de plano de saúde. Cad Saúde Colet. 2012;20(1):64-71.

Fadare JO, Oshikoya KA, Ogunleye OO, Desalu OO, Ferrario A, Enwere OO, et al. Drug promotional activities in Nigeria: impact on the prescribing patterns and practices of medical practitioners and the implications. Hosp Pract (1995). 2018;46(2):77-87.

Faleiros DR, Acurcio FA, Álvares J, Nascimento RCRM, Costa EA, Guibu IA, et al. Financing of Pharmaceutical Services in the municipal management of the Brazilian Unified Health System. Rev Saude Publica. 2017;51 (suppl 2):14s.

Galvao TF, Silva MT, Gross R, Pereira MG. Medication use in adults living in Brasilia, Brazil: a cross-sectional, populationbased study. Pharmacoepidemiol Drug Saf. 2014;23(5): 507-14.

Garcia LP, Sant'Anna AC, Magalhães LCGd, Freitas LRSd, Aurea AP. Gastos das famílias brasileiras com medicamentos segundo a renda familiar: análise da Pesquisa de Orçamentos Familiares de 2002-2003 e de 2008-2009. Cadernos de Saúde Pública. 2013;29(8):1605-16.

Gomes VP, Silva MT, Galvão TF. Prevalência do consumo de medicamentos em adultos brasileiros: uma revisão sistemática. Ciência \& Saúde Coletiva. 2017;22(8):2615-26.

Haque M. Essential Medicine Utilization and Situation in Selected Ten Developing Countries: A Compendious Audit.
Journal of International Society of Preventive \& Community Dentistry. 2017;7(4):147-60.

Hoebert J, Laing R, Stephens P. The World Medicines Situation 2011: pharmaceutical consumption. 3 ed. Geneva: World Health Organization; 2011.

Naves JdOS, Castro LLCd, Carvalho CMSd, MerchánHamann E. Automedicação: uma abordagem qualitativa de suas motivações. Ciência \& Saúde Coletiva. 2010;15(suppl 1):1751-62.

Oliveira MA, Luiza VL, Tavares NUL, Mengue SS, Arrais PSD, Farias MR, et al. Access to medicines for chronic diseases in Brazil: a multidimensional approach. Rev Saude Publica. 2016;50(Suppl 2):6s.

Parmar D, Stavropoulou C, Ioannidis JP. Health outcomes during the 2008 financial crisis in Europe: systematic literature review. BMJ. 2016;354:i4588.

Pons EDS, Knauth DR, Vigo A, Mengue SS. Predisposing factors to the practice of self-medication in Brazil: Results from the National Survey on Access, Use and Promotion of Rational Use of Medicines (PNAUM). PLoS One. 2017;12(12):e0189098.

Prado MA, Francisco PM, Bastos TF, Barros MB. Use of prescription drugs and self-medication among men. Rev Bras Epidemiol. 2016;19(3):594-608.

Programa das Nações Unidas Para o Desenvolvimento. Atlas do Desenvolvimento Humano no Brasil. RM-Manaus. Brasilia: PNUD; 2013 [Available from: http://www. atlasbrasil.org.br/2013/pt/perfil_rm/manaus.

Silva MT, Galvao TF. Use of health services among adults living in Manaus Metropolitan Region, Brazil: populationbased survey, 2015. Epidemiol Serv Saúde. 2017;26(4): 725-34.

Wettermark B, Martino MD, Elseviers M. Study designs in drug utilization research. Drug Utilization Research: John Wiley \& Sons, Ltd; 2016. p. 13-28.

WHO. Collaborating Centre for Drug Statistics Methodology, ATC classification index with DDDs, 2019. Oslo, Norway 2018. [cited 02/11/2018]. Available from: http://www.whocc. no/atc_ddd_index/.

Received for publication on $19^{\text {th }}$ September 2018 Accepted for publication on $16^{\text {th }}$ May 2019 